\title{
Post Market In-vitro Bioequivalence Study on Representative Brands of Ciprofloxacin Tablets (500 mg) Prescribed in Typhoid Disease
}

\author{
Muhammad Azeem ${ }^{1,2, *}$, Humaira Naureen ${ }^{1}$, Madeeha Malik ${ }^{2}$ \\ ${ }^{1}$ Department of Pharmaceutics, Riphah Institute of Pharmaceutical Sciences, Islamabad, Pakistan \\ ${ }^{2}$ Department of Pharmacy, Hamdard Institute of Pharmaceutical Sciences, Islamabad, Pakistan \\ *Corresponding author: azeem.hamdard@gmail.com
}

Received October 15, 2014; Revised November 20, 2014; Accepted December 04, 2014

\begin{abstract}
Seven brands of ciprofloxacin (One multinational and six local) were evaluated in terms of their bioavailability and efficacy. Pharmaceutical Parameters like weight variation, hardness, disintegration, dissolution and content assay were determined. Antibacterial susceptibility assay was performed on standard Strain of Salmonella typhi (ATCC 14028). MIC and ZOI were assessed. The results of the study indicated that three local brands had content less than the stated claim of USP and one brand did not pass the disintegration and dissolution tests, so they cannot be used as therapeutic alternatives. Antibacterial assay showed less MIC value of the brands having greater drug content while drug with lesser amount had greater MIC value. Similarly, one local brand showed greater zone of inhibition (ZOI) as compared to multinational brand having more price than the local brand.
\end{abstract}

Keywords: minimum Inhibitory concentration (MIC), zone of inhibition (ZOI), United States Pharmacopoeia (USP), World Health Organization (WHO), Gastro-Intestinal Track (GIT), Muller Hinton Agar (MHA), Irrational Drug Use (IRDU)

Cite This Article: Muhammad Azeem, Humaira Naureen, and Madeeha Malik, "Post Market In-vitro Bioequivalence Study on Representative Brands of Ciprofloxacin Tablets (500 mg) Prescribed in Typhoid Disease.” American Journal of Pharmacological Sciences, vol. 2, no. 5B (2014): 8-11. doi: 10.12691/ajps-2-5B-3.

\section{Introduction}

Post market study involves the monitoring of drugs after being marketed to the local public for its efficacy and standard [1]. Typhoid fever, one of the major bacterial infections worldwide, is caused by the human-adapted S.Entericaserovar Typhi [1]. For every ten cases of S.Typhi infection, there are one or two cases of paratyphoid fever, caused by the human-adapted $S$. Enterica serovars Paratyphi A, Paratyphi B and Paratyphi C [1]. In developing countries, typhoid is considered as a major health problem. According to WHO, approximately 500,000 deaths are reported each year globally. This disease is prevalent in India, Africa and Central America, where supply of pure water is scarce. Typhoid fever is the sixth most common cause of death in Pakistan. In Pakistan, the prevalence of typhoid is estimated to be 412 cases per 100,000 populations per year [2]. In India the prevalence of typhoid in each year is estimated to be 214.2 per 100,000 [3]. S. enteric species are typically orally acquired pathogens that cause one of four major syndromes: enteric fever (typhoid), enterocolitis/diarrhea, bacteremia and chronic asymptomatic carriage [4]. In Pakistan epidemiology of typhoid fever with in the country is heterogeneous both in terms of time and location. Cases of typhoid fever are greater in areas where rainfall is greater like Rawalpindi and Faisalabad as compared to areas where rainfall is less and moderate like Multan and Lahore [5]. Treatment of typhoid disease in past was preferred by oral antibiotics particularly Chloramphenicol, amoxicillin, ciprofloxacin etc. But with the emergence of multidrug resistantance, intravenous cephalosporins are now being used to treat infection [6].

"Rationale use of drugs requires that patients receive medications appropriate to the clinical needs, in doses that meet their own individual requirements for an adequate period of time, at the lowest cost to them and their community". There are number of factors which cause treatment failure of typhoid. Among them late diagnosis of the disease, incompliance to the medications due to affordability issue, lack of knowledge and adherence to the standard treatment guidelines and availability of substandard formulations etc leads to the development of extensively drug resistance typhoid [7].

\section{Methodology}

All the seven Brands were purchased from Retail pharmacies of Islamabad. Standard ciprofloxacin was gifted by Wilson Pharmaceuticals for conduction of research. Bacterial Strain was purchased from local supplier "The Scientific Laboratories”. The reagents used included Hydrochloric acid, ferric chloride, MHA, 
nutrient broth agar. The brands were given codes and these codes are used. Cipro-1 is a multinational brand, while cipro-2, cipro-3, cipro-4, cipro-5, cipro-6 and cipro-

7 all are local company brands (Table 1 ).

Table 1. Samples of Ciprofloxacin Tablets

\begin{tabular}{|c|c|c|c|c|c|c|}
\hline Sr.no & Brands & Company & Batch no & License no & Reg no & Exp Date \\
\hline 1 & Cipro-1 & Bayer's Pharma & KHO1161 & 000003 & 013329 & 9/2018 \\
\hline 2 & Cipro-2 & Wilson Pharma & 6140 & 00239 & 016728 & 07/2016 \\
\hline 3 & Cipro-3 & Warafanapharma & $13 F 0220$ & 000720 & 072302 & $6 / 2015$ \\
\hline 4 & Cipro-4 & AmsonPharma & 380 & 000393 & 017352 & $01 / 2017$ \\
\hline 5 & Cipro-5 & Pearl Pharma & 3110 & 000479 & 033359 & $02 / 2017$ \\
\hline 6 & Cipro-6 & Max Pharma & T015 & 000671 & 068588 & 03/2016 \\
\hline 7 & Cipro-7 & Sami Pharma & $010 \mathrm{~N}$ & 000072 & 011837 & $12 / 2016$ \\
\hline
\end{tabular}

\subsection{Weight Variation Test}

Twenty individual tablets of each brand were weighed on analytical weighing balance. The mean, average and percentage deviation was assessed. For tablets weighing more than 500mg, the individual tablet must be in range of $\pm 5 \%$ according to USP standards.

\subsection{Hardness Test}

The resistance of a tablet to physical abrasion or crushing depends upon its hardness. Ten tablets of each brand were taken and their crushing strength was determined with a tablet hardness tester (Monsanto hardness tester). Average hardness was assessed.

\subsection{Disintegration test}

Six tablets from each brand were randomly selected and were employed for disintegration test using freshly prepared $0.1 \mathrm{~N} \mathrm{HCl}$ solution at $37^{\circ} \mathrm{C} \pm 1$. The tablets should comply with in the specified time limit that is ten minutes. The disintegration time is the time taken where no particles of the tablet remains on the basket assembly of the apparatus [3].

\subsection{Dissolution Test}

Dissolution test is performed to assess the amount or percentage of drug released from a formulation under simulated conditions of GIT provided during in-vitro analysis. Six tablets of each brand were taken and dissolved in $900 \mathrm{~mL}$ of $0.01 \mathrm{~N}$ HCL solution using apparatus II paddle method. After thirty minutes the sample was taken, filtered and assayed using UVspectroscope at $277 \mathrm{~nm}$ wavelength to determine the amount of ciprofloxacin released from the tablets.

\subsection{Drug Content Assay}

A solution of $1 \% \mathrm{w} / \mathrm{v}$ of ferric chloride was freshly prepared. Another solution of $100 \mathrm{mcg} / \mathrm{mL}$ of pure ciprofloxacin was prepared. Five tablets from each brand were crushed and $100 \mathrm{mg}$ of the powdered samples were weighed, dissolved in $100 \mathrm{~mL}$ of $0.1 \mathrm{~N}$ hydrochloric acid and further dilution was made upto $100 \mathrm{mcg} / \mathrm{mL}$ or each brand. To $5 \mathrm{~mL}$ of each brand and pure sample, $1 \mathrm{~mL}$ of ferric chloride was added and made up to $50 \mathrm{~mL}$ with $0.1 \mathrm{~N}$ $\mathrm{HCl}$. The absorbance of each sample was taken at $438 \mathrm{~nm}$ against blank reagent with an ultraviolet spectrophotometer. The percentage content was calculated for each brand [1].

\subsection{Anti-bacterial Activity}

\subsubsection{MIC Determination}

Minimum inhibitory concentration is the lowest concentration, amount of the drug at which it shows the highest activity against microorganisms [8,9]. MIC was determined by broth dilution method. All seven herbal and seven allopathic formulations along with the standard ciprofloxacin was assessed and their MIC was determined.

\subsubsection{Preparation of Inoculum}

Standard stock of bacterial isolate was prepared by suspending a loop full of microbial growth in $4 \mathrm{~mL}$ of distilled water. It was incubated at $37^{\circ} \mathrm{C}$ for 12 hours and then its turbidity was compared with 0.5 McFarland's standard giving a bacterial load of about $3.6 \times 102 \mathrm{cfu}$ $/ \mathrm{mL}[9]$.

\subsubsection{Preparation of Antimicrobial Solutions}

One tablet of $500 \mathrm{mg}$ was dissolved in $10 \mathrm{~mL}$ of sterile water. This gives concentration of $50 \mathrm{mg} / \mathrm{mL}$. It was further diluted through two-fold dilution method and a series of serial dilutions were made from 1 to $12 \mu \mathrm{g} / \mathrm{mL}$. Similarly herbal formulations were diluted using sterile water.

\subsubsection{Preparation of Media}

Muller Hinton Broth media was prepared by using manufacturer's guidelines. It was then autoclaved at $121^{\circ} \mathrm{C}$ at $15 \mathrm{psi}$ pressure for 15 minutes. It was then allowed to cool. This media was poured in sterile test tubes under aseptic conditions using laminar flow Hood.

\subsubsection{Inoculation and Incubation}

One microliter of the bacterial isolate suspension was taken through micropipette and was inoculated in the test tube containing $\mathrm{MH}$ broth media. Then one milliliter of each dilution of the antimicrobial agents of all allopathic was poured in the test tube. These test tubes were incubated at $37^{\circ} \mathrm{C}$ for $18-24$ hours.

\subsection{Determination of Zone of Inhibition}

\subsubsection{Preparation of Media}

Muller Hinton agar was dissolved is distilled water and simultaneously heated until it gets boiled. Then the media was poured in a conical flask and along with glass petri plates and autoclaved at $121^{\circ} \mathrm{C}$ and 15 psi for 15 minutes. 
Then under aseptic conditions these petri plates were filled with MHA and allowed to solidify.

\subsubsection{Inoculation and Incubation}

After solidification of the medium, sterile cotton swab was dipped in the bacterial inoculum and was spread over the medium on plate. Then using a sterile cork borer of $8 \mathrm{~mm}$ diameter, wells were made and approximately $100 \mathrm{uL}$ of the stock solutions of the standard drug and other formulations of allopathic drugs were incorporated. These plates were divided into four portions and were labeled. After allowing the drug to diffuse these plates were incubated at $37^{\circ} \mathrm{C}$ for 24 hours [8]. Zone of inhibition was measured for all allopathic formulations.

\section{Results}

\subsection{Weight Variation Test}

Results for weight variations showed that all the brands were within the specified limit that is $\pm 5 \%$. Not a single tablet deviates from this limit. The average weight of cipro-2 was greater than all other brands. The minimum average weight was that of cipro-5. The results in decreasing order are as, cipro- $2>$ cipro- $4>$ cipro- $6>$ cipro-1 > cipro-3 > cipro-7 > cipro-5 (Table 2).

Table 2. Results of Weight Variation Test

\begin{tabular}{|c|c|c|c|}
\hline \multicolumn{4}{|c}{ Table 2. Results of Weight Variation Test } \\
\hline Sr. no & Brands & Average weight (mg) & \% Deviation \\
\hline 1 & Cipro-1 & 773.3 & -0.023 \\
\hline 2 & Cipro-2 & 904.85 & -0.00525 \\
\hline 3 & Cipro-3 & 744.45 & 0.0027 \\
\hline 4 & Cipro-4 & 816.1 & -0.0118 \\
\hline 5 & Cipro-5 & 670.9 & 0.00045 \\
\hline 6 & Cipro-6 & 773.55 & 0.0001 \\
\hline 7 & Cipro-7 & 726.3 & 0.0039 \\
\hline
\end{tabular}

\subsection{Hardness Test}

Results showed that cipro-3 has highest value for hardness that is $12 \mathrm{~kg} / \mathrm{cm}^{2}$, while cipro-5 has the least value that is $7.61 \mathrm{~kg} / \mathrm{cm}^{2}$. Values for hardness in decreasing order are cipro-3 $>$ cipro- $1>$ cipro-6 $>$ cipro$2>$ cipro- $4>$ cipro-7 $>$ cipro-5 (Table 3 ).

Table 3. Results for Hardness test

\begin{tabular}{|c|c|c|}
\hline \multicolumn{2}{|c|}{ Table 3. Results for Hardness test } \\
\hline 1 & Brands & Average Hardness $\mathbf{( k g / \mathbf { c m } ^ { 2 } )}$ \\
\hline 2 & Cipro-1 & 9.5 \\
\hline 3 & Cipro-2 & 8.2 \\
\hline 4 & Cipro-3 & 12 \\
\hline 5 & Cipro-4 & 8.02 \\
\hline 6 & Cipro-5 & 7.61 \\
\hline 7 & Cipro-6 & 9.3 \\
\hline
\end{tabular}

\subsection{Disintegration Test}

Six tablets of each brand were taken and their disintegration tests were performed, temperature was maintained at $37^{\circ} \mathrm{C} \pm 1$. The maximum time for disintegration was taken by cipro-3 that was 55 minutes. The minimum time was taken by cipro-7 that was 1 minute. Results for disintegration time in decreasing order are as cipro-3 $>$ cipro-2 > cipro-6 > cipro-4 > cipro- $1>$ cipro-5 > cipro-7 (Table 4).

Table 4. Results for Disintegration Test

\begin{tabular}{|c|c|c|}
\hline Sr. no & Brands & Average Disintegration Time (minutes) \\
\hline 1 & Cipro-1 & 1.28 \\
\hline 2 & Cipro-2 & 8.32 \\
\hline 3 & Cipro-3 & 55 \\
\hline 4 & Cipro-4 & 2.57 \\
\hline 5 & Cipro-5 & 1.16 \\
\hline 6 & Cipro-6 & 3.7 \\
\hline 7 & Cipro-7 & 1 \\
\hline
\end{tabular}

\subsection{Dissolution Test}

Dissolution test was performed to check the percentage of drug released from the formulation after thirty minutes. The amount of drug released was analyzed by Uvspectroscopy. The maximum \% of drug released was $101.03 \%$ from cipro-4. The minimum amount of drug was released by cipro-3 that was 39.8\%. Cipro-7 released $76.7 \%$ of the drug after thirty minutes. Cipro-1, cipro-2, cipro-5 and cipro-6 showed 97.3\%, 93.7\%. 86.82\% and 93.4\% respectively (Table 5).

Table 5. Results of Dissolution test

\begin{tabular}{|c|c|c|}
\hline Sr. no & Brands & \%age of drug released after 30 minutes \\
\hline 1 & Cipro-1 & 97.3 \\
\hline 2 & Cipro-2 & 93.7 \\
\hline 3 & Cipro-3 & 39.8 \\
\hline 4 & Cipro-4 & 101.03 \\
\hline 5 & Cipro-5 & 86.82 \\
\hline 6 & Cipro-6 & 93.4 \\
\hline 7 & Cipro-7 & 76.7 \\
\hline
\end{tabular}

\subsection{Drug Content Assay}

The United States Pharmacopoeia (2005) states that the content of ciprofloxacin should not differ from the stated dose by more than $10 \%$ [6] The results showed that all the brands had amount of active drug $>90 \%$ except to that of cipro-3 which had $63.45 \%$, cipro-2 had $88.75 \%$,cipro-6 had $88.9 \%$ of the total amount of active drug. Cipro- 4 had the maximum amount of drug content that was $106.06 \%$. While cipro-1 had $91.28 \%$, cipro-2 had $88.75 \%$, cipro-5 had $91.5 \%$, and cipro-7 had $97.2 \%$ of the active drug content respectively (Table 6).

Table 6. Results of Drug Content Assay

\begin{tabular}{|c|c|c|c|c|}
\hline Sr.No & Brands & $\begin{array}{c}\text { Drug Content } \\
\text { (mg) }\end{array}$ & $\begin{array}{c}\text { \%age Drug } \\
\text { Content }\end{array}$ & $\begin{array}{c}\text { \% Drug Content } \\
\text { Deviation }\end{array}$ \\
\hline 1 & Cipro-1 & 456.4 & 91.28 & -8.72 \\
\hline 2 & Cipro-2 & 443.75 & 88.75 & -11.25 \\
\hline 3 & Cipro-3 & 317.28 & 63.45 & -36.54 \\
\hline 4 & Cipro-4 & 530.3 & 106.06 & 6.06 \\
\hline 5 & Cipro-5 & 457.58 & 91.5 & -8.484 \\
\hline 6 & Cipro-6 & 444.5 & 88.9 & -11.1 \\
\hline 7 & Cipro-7 & 486.06 & 97.2 & -2.788 \\
\hline
\end{tabular}




\subsection{Determination of MIC and Zone of Inhibition}

\subsubsection{Minimum Inhibitory Concentrations}

Minimum inhibitory concentration was determined for all the brands including seven allopathic brands of ciprofloxacin formulations along with that of the standard ciprofloxacin. Results showed that all the allopathic brands showed antibacterial activity. The least MIC value was shown by cipro- $4(1 \mu \mathrm{g} / \mathrm{mL})$ and the maximum value for MIC was shown by cipro-3 (3.2 $\mu \mathrm{g} / \mathrm{mL}$ ) (Table 7).

Table 7. Results for MIC of Samples

\begin{tabular}{|c|c|c|}
\hline Sr. no & Brands & $\begin{array}{c}\text { Minimum inhibitory } \\
\text { concentration }(\boldsymbol{\mu g} / \mathbf{m L})\end{array}$ \\
\hline 1 & Cipro-1 & 1.8 \\
\hline 2 & Cipro-2 & 2 \\
\hline 3 & Cipro-3 & 3.2 \\
\hline 4 & Cipro-4 & 1 \\
\hline 5 & Cipro-5 & 1.8 \\
\hline 6 & Cipro-6 & 2 \\
\hline 7 & Cipro-7 & 1.4 \\
\hline 8 & Standard Ciprofloxacin & 1.2 \\
\hline
\end{tabular}

\subsubsection{Zone of Inhibitions}

Zone of Inhibitions was determined after knowing the minimum inhibitory concentrations of all allopathic formulations. As the average MIC value of all the allopathic ciprofloxacin was near to $2 \mu \mathrm{g} / \mathrm{mL}$, zone of inhibitions were determined at $2 \mu \mathrm{g} / \mathrm{mL}, 4 \mu \mathrm{g} / \mathrm{mL}, 6 \mu \mathrm{g} / \mathrm{mL}$, $8 \mu \mathrm{g} / \mathrm{mL}, 10 \mu \mathrm{g} / \mathrm{mL}$ and $12 \mu \mathrm{g} / \mathrm{mL}$. Results showed that local brands of ciprofloxacin were more effective and gave bigger zone of inhibition than the multinational brand cipro-1 (Table 8).

Table 8. Results for Zone of Inhibition

\begin{tabular}{|c|c|c|c|c|c|c|c|}
\hline \multirow[b]{2}{*}{ Sr.no } & \multirow[b]{2}{*}{ Brands } & \multicolumn{6}{|c|}{ Zone of Inhibition ( $\mathrm{mm}$ ) at 24 hours } \\
\hline & & $\begin{array}{c}2 \mu \mathrm{gg} / \\
\mathrm{mL}\end{array}$ & $\begin{array}{c}4 \mu \mathrm{g} / \\
\mathrm{mL}\end{array}$ & $\begin{array}{c}6 \mu \mathrm{g} / \\
\mathrm{mL}\end{array}$ & $\begin{array}{c}8 \mu \mathrm{g} / \\
\mathrm{mL}\end{array}$ & $\begin{array}{c}10 \mu \mathrm{g} / \\
\mathrm{mL}\end{array}$ & $\begin{array}{c}12 \mu \mathrm{g} / \\
\mathrm{mL}\end{array}$ \\
\hline 1 & Cipro-1 & 11 & 14 & 15 & 18 & 20 & 22 \\
\hline 2 & Cipro-2 & 13 & 15 & 18 & 20 & 21 & 23 \\
\hline 3 & Cipro-3 & 6 & 9 & 10 & 12 & 14 & 15 \\
\hline 4 & Cipro-4 & 15 & 17 & 18 & 19 & 22 & 24 \\
\hline 5 & Cipro-5 & 10 & 11 & 11 & 13 & 15 & 17 \\
\hline 6 & Cipro-6 & 11 & 12 & 14 & 17 & 19 & 22 \\
\hline 7 & Cipro-7 & 10 & 14 & 16 & 19 & 20 & 21 \\
\hline 8 & $\begin{array}{c}\text { Standard } \\
\text { Ciprofloxacin }\end{array}$ & 14 & 19 & 20 & 21 & 23 & 25 \\
\hline
\end{tabular}

\section{Conclusion}

The results revealed that three local (cipro-2, cipro-3, cipro-6) brands were below standard in content assay as per USP standards and cipro-3 has maximum values for disintegration and dissolution time which were out of the standard values according to USP. The results of present study regarding MIC of ciprofloxacin showed that the brand with maximum drug content (cipro-4) had least MIC value and the brand having minimum drug content (cipro-3) had the maximum MIC value against S.typhi. Local brands cipro- 2 and cipro- 4 showed greater zone of inhibitions than the multinational brand cipro-1.

Findings of the current study revealed that lack of treatment guidelines, peer influence of prescribers, influence of pharmaceutical industries might be the contributing factors towards IRDU which resulted in increased treatment cost. Availability of brands having sub-standard levels of the active agent results in resistance to typhoid and ultimately increases the cost of therapy. On the other hand, local brands can be used as therapeutic alternatives to multinational brands which showed greater activity against microorganism and had maximum drug content with least price in market. So Government and Ministry of health should take necessary steps in promoting cost effective treatment of typhoid, in regulating quality and standard of allopathic formulations

\section{References}

[1] N. C. Ngwuluka, k. lawal, P. O. olorunfemiand N. A. Ochekpe. Post-market in vitro bioequivalence study of six brands of ciprofloxacin tablets/caplets in jos, Nigeria, Scientific research and essay, Vol. 4 (4), pp. 298-305, April, 2009.

[2] Raheela. B, Shahnaz. G, Syed Baqir. S.N and Shoukat.M. Pharmaceutical evaluation of different brands of levofloxacin tablets (250mg) available in local market of Karachi (Pakistan), International Journal of Current Pharmaceutical Research, Vol 3, issue1, 1522.

[3] Osonwa Uduma E., Agbokeayodeji A., Amadi Rosemary C., Okorie, Ogbonna and Opurum Christian C Bioequivalence studies on some selected brands of ciprofloxacin hydrochloride tablets in the Nigerian market with ciproflox as innovator brand, Journal of applied pharmaceutical science, 01 (06); 2011: 80-84.

[4] Sajib Chakra B, \& Zakaria A, Study of antimicrobial activity of ayurvedic and Unani medicine and their comparative analysis with commercial antibiotics, International journal of research in applied, natural and social sciences, Vol. 1, issue 3, Aug 2013, 63-74.

[5] The United States Pharmacopoeia. United States Pharmacopoeia convention inc; Rockville, 2005.

[6] Paulwilson, Sebastian E. Winter, Andreas J. Baumler. Clinical pathogenesis of typhoid fever. Department of medical microbiology and immunology, school of medicine, university of California, J infect developing countries 2008; 2(4): 260-266.

[7] Hayat,A.S, Shaikh,N. Evaluation of Typhidot (igm) in early and rapid diagnosis of typhoid fever. Professional med journal, 2011. 18(2): 259-264.

[8] Ghosh,S, Batabyal. P, Rajendran.K, PalitA. Typhoid fever in rural communities of West Bengal, India, Indian council of medical research, 2010: page 219-221.

[9] Bryan C, Guntram A Grassl, Salmonella, the host and disease: A brief review, Immunology and cell biology, (2007) 85, 112-118. 